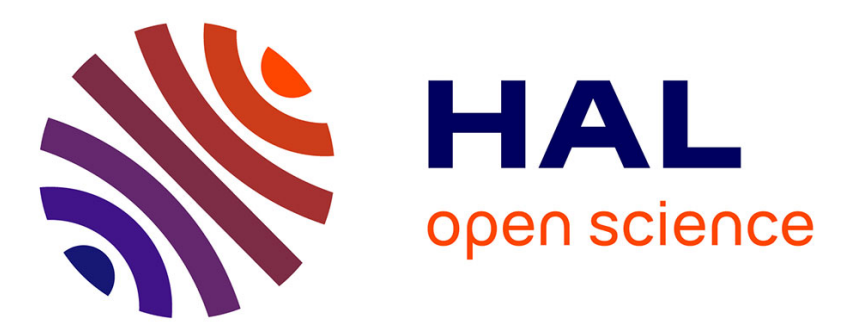

\title{
Coupled Electronic and Magnetic Fast Simulation for High-Speed Permanent-Magnet Drive Design
}

Mathieu Gerber, Adrien Gilson, Daniel Depernet, Frédéric Dubas, Christophe Espanet, Gaël Andrieux

\section{- To cite this version:}

Mathieu Gerber, Adrien Gilson, Daniel Depernet, Frédéric Dubas, Christophe Espanet, et al.. Coupled Electronic and Magnetic Fast Simulation for High-Speed Permanent-Magnet Drive Design. Vehicle Power and Propulsion Conference, Oct 2016, Hangzhou, China. hal-02130750

\section{HAL Id: hal-02130750 https://hal.science/hal-02130750}

Submitted on 16 May 2019

HAL is a multi-disciplinary open access archive for the deposit and dissemination of scientific research documents, whether they are published or not. The documents may come from teaching and research institutions in France or abroad, or from public or private research centers.
L'archive ouverte pluridisciplinaire HAL, est destinée au dépôt et à la diffusion de documents scientifiques de niveau recherche, publiés ou non, émanant des établissements d'enseignement et de recherche français ou étrangers, des laboratoires publics ou privés. 


\section{Coupled Electronic and Magnetic Fast Simulation for High-Speed Permanent-Magnet Drive Design}

\author{
Mathieu Gerber, Adrien Gilson, \\ Christophe Espanet and Gaël Andrieux \\ Research and Development Department \\ Moving Magnet Technologies \\ Besançon, France \\ mathieu.gerber@movingmagnet.com
}

\begin{abstract}
The interest in high speed electrical machines for automotive applications has increased recently. This includes electrically-assisted turbochargers (EAT), air compressors for fuel-cells and waste heat recovery (WHR) generators. For these kinds of application working in elevated temperature environments, the losses in the machine and in the power electronics should be carefully analyzed. In this context, this paper presents a coupled electronic and magnetic simulation and its application on a high-power high-speed motor. The coupling between the two models is mainly linked to the phase currents and their impact on the electronic driver. In addition, motor performances must be considered to optimize the overall system efficiency. However, optimizations of electronic driver and electric motor are very time-consuming since they are based on finite element methods for magnetic simulations and on Kirchhoff equations resolution for electronic simulations. Therefore, this paper presents a fast coupled model to increase the computation speed and its application to optimize a system using a high-power high-speed motor with special focuses on motor rotor losses and overall efficiency.
\end{abstract}

Keywords-High-speed drive; Electronic modeling; PM Motor modeling; System modeling; System optimization

\section{INTRODUCTION}

The growing interest in high-speed electrified systems in automotive applications requires to design electronic drivers and electric motors with new approaches taking into account the strong coupling between the two parts of the drive. Typical applications include electrically-assisted turbochargers (EAT), air compressors for fuel-cells or waste heat recovery (WHR) generators. These kinds of high-speed drives require a significant increase of the energy conversion frequencies typically up to a few $\mathrm{kHz}$ for the motor and several tens of $\mathrm{kHz}$ for the power electronics. This leads to high iron and eddy current losses in both stator and rotor and also causes increased switching losses in the converter. In addition, system optimization has to consider both motor and electronic losses while taking into account the constraints of size and temperature. Indeed, the size is generally strongly limited in embedded applications and the ambient temperature may reach up to $110^{\circ} \mathrm{C}$ in the particular case of automotive systems. Furthermore, an elevated temperature environment leads to high constraints on the electronic driver components (usually limited to $175^{\circ} \mathrm{C}$ for classic automotive MOSFETs), motor magnets (limited to about $220^{\circ} \mathrm{C}$ for $\mathrm{NdFeB}$ and $300^{\circ} \mathrm{C}$ for

\author{
Daniel Depernet and Frédéric Dubas \\ ENERGY Department \\ FEMTO-ST Institute, \\ University of Bourgogne Franche-Comté \\ Belfort, France
}

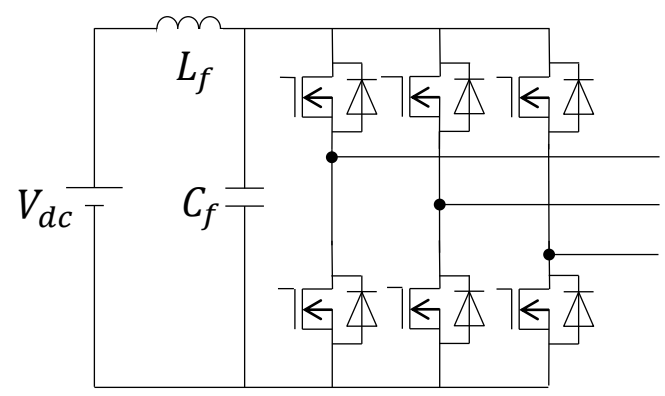

Fig. 1. 3-phase 2-level voltage source inverter with an input $L_{f}, C_{f}$ filter, $V_{d c}$ and $i_{d c}$ are respectively the DC-bus voltage and current.

SmCo magnets), windings and bearings. Thus, the main system constraints require minimizing rotor losses to limit permanent magnets temperature rise as well as switching losses to limit maximum semi-conductor junction temperature. Finally, the reduction of losses allows increasing the overall system efficiency.

In this paper, electronic and magnetic models are based on harmonic calculations. Firstly, the electronic model will be described. This model provides an efficiency estimation based on the motor parameters, DC-bus level and control mode parameters: DC-bus control mode parameters allow to calculate the voltage applied across motor phases and then the phase currents are deduced from those voltages and the motor parameters. The modeling target is a fast current calculation from phase voltages and motor parameters by computing the voltage harmonics generated by the electronic driver. From the currents and voltages switched by the driver, switch losses and power electronics efficiency are calculated.

Secondly, the motor model based on a 2-D analytical subdomain model will be described. This model consists in analytically solving the Maxwell equations in different regions and, by applying boundary conditions, to obtain the magnetic vector potential in the machine. It computes static motor parameters (which are then used in the electronic model) and all losses generated by the currents injected by the electronic driver into motor phases, i.e. detailed iron, copper and rotor losses.

Finally, the electronic and magnetic coupling will be presented and applied on a given study case. An electronic driver and a given permanent-magnet synchronous machine 
(PMSM) will be chosen from the constraint parameters. The model results are presented to highlight the benefit of applying this model.

\section{ELECTRONIC MODEL DESCRIPTION}

In automotive applications, voltage source inverters (VSI) with MOSFETs as controllable switches (Fig. 1), are mainly used to drive 3-phase PMSM [1]. A VSI can synthesize sinusoidal or trapezoidal currents according to the electronic control mode selected.

For high-speed motor, due to a high fundamental frequency and low inductance values, sinusoidal currents require high switching frequencies and significant calculation resources to ensure an efficient field oriented control (FOC). The impact of different pulse-width modulation (PWM) strategies will be studied on the motor losses. Trapezoidal currents require less elevated switching frequencies and computing power because the voltage vectors are directly commutation signals of Hall probes. However, trapezoidal currents can lead to dramatically high rotor losses impossible to be cooled. The following subsections focus on voltage and current equations, power electronic losses and PWM strategies descriptions.

\section{A. Electronic Model}

The electronic model is developed for a given operating point in steady state. The model is based on a fundamental analysis of the voltage $v$ from the current $i$ flowing in the motor and given by the following equation:

$$
v(t)=R i(t)+L_{s} \frac{d i(t)}{d t}+e(t)
$$

where $R$ and $L_{s}$, respectively, are the phase resistance and cyclic inductance and $e$ the back-EMF. Then the voltage reference is computed by a fundamental harmonic calculation using the following complex equation derived from (1):

$$
\underline{V}\left(\omega_{e}\right)=\left(R+j L_{s} \omega_{e}\right) \underline{I}\left(\omega_{e}\right)+\underline{E}\left(\omega_{e}\right)
$$

where $\omega_{e}$ is the electric pulse frequency. The voltage reference module and phase is computed on the motor and provides the reference signal. VSI model gives the phase-to-neutral voltage from the switch command and DC-bus voltage. This voltage is directly used to compute the current flowing in the motor phases and generated by the electronic driver.

A fast Fourier transform is performed on the voltage signal and the generated current is then computed from equation (1) for each harmonic $k$ as follows:

$$
\underline{I}\left(k \omega_{e}\right)=\frac{\underline{V}\left(k \omega_{e}\right)+\underline{E}\left(k \omega_{e}\right)}{R+j L_{s} k \omega_{e}}
$$

\section{B. VSI Loss Evaluation}

From the currents and voltages generated by the power switches, the electronic efficiency can be computed from the MOSFETs and diodes commutation times and on-state resistance. Automotive VSI are mainly designed with MOSFETs due to the low voltage available on the DC-bus (generally $12 \mathrm{~V}, 24 \mathrm{~V}, 36 \mathrm{~V}$ or $48 \mathrm{~V}$ ).

\section{1) MOSFET}

MOSFET average conductive state losses $P_{M O S_{\text {cond }}}$ are calculated by the average losses during an electrical period $T_{e}$ with the following classical formula:

$$
P_{M O S_{\text {cond }}}=\frac{1}{T_{e}} \int_{0}^{T_{e}} R_{D S_{O N}} I_{D}{ }^{2}(t) d t
$$

where $R_{D S_{O N}}$ is the specific on-state resistance when the MOSFET conducts and $I_{D}$ is the drain current which flows across the power device.

MOSFET commutation losses $P_{M O S_{S W}}$ are created during turn-on $t_{o n}$ and turn-off $t_{\text {off }}$ of the voltage $V_{D}$ across the MOSFET and the current $I_{D}$ which flows from the drain to the source at the PWM frequency $f$. Those losses can be approximated by the following formula:

$$
P_{M O S_{s w}}=\frac{1}{2}\left(t_{o n}+t_{o f f}\right) V_{D} I_{D} f
$$

\section{2) Diode}

Dead time intervals are required to avoid cross conduction between high side and low side MOSFETs. During those blank times, diodes conduct and generate losses. Conduction losses of the diodes $P_{\text {diode }_{\text {cond }}}$ result from the current $I_{f}$ and the voltage drop $V_{f}$ across. Those losses are computed with equation (6).

$$
P_{\text {diode }_{\text {cond }}}=\frac{1}{T_{e}} \int_{0}^{T_{e}} V_{f} I_{f}(t) d t
$$

The reverse recovery losses $P_{\text {diode }_{R R}}$ are created by the internal charge of the diode stored during the conduction. The reverse recovery charge $Q_{r r}$ must be depleted at the PWM frequency $f$ on the DC-bus voltage $V_{d c}$. Then, the corresponding losses are given with the following equation:

$$
P_{\text {diode }_{R R}}=f Q_{r r} V_{d c}
$$

By computing (8) during an entire electrical period, an approximation of the converter efficiency on a given operating point and in steady state can be calculated. Those losses can be greatly reduced by using a metal interface like in a Schottky diode.

Finally, the total losses of the inverter $P_{\text {inverter }}$ are computed by the following formula:

$$
\begin{gathered}
P_{\text {inverter }}=6 \cdot\left(P_{\text {MOS }_{\text {cond }}}+P_{M O S_{S w}}\right. \\
\left.+P_{\text {diode }_{\text {cond }}}+P_{\text {diode }_{R R}}\right)
\end{gathered}
$$

\section{3) PWM Strategies}

Space vector pulse width modulation (SVPWM) is mainly used in vector control. This over-modulation strategy is usually chosen to use the maximum battery voltage [11]. The drawback of this modulation strategy lies in commutation losses for high PWM frequencies.

Another strategy that can be used is the general discontinuous pulse width modulation (GDPWM) to reduce the commutation losses [11]. Commutation losses are lowered by clamping references applied to the motor. 


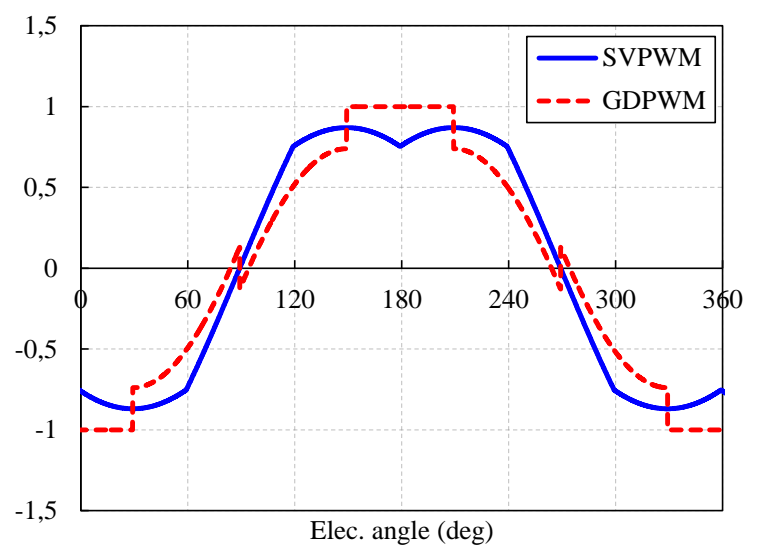

Fig. 2. Space vector and general discountinuous PWM references.

Fig. 2 shows the resulting voltage waveforms for both strategies. GDPWM and SVPWM influences on motor currents losses are investigated in the last part.

\section{THE ELECTRICAL MACHINE}

\section{A. Analytical Model}

Design of high-speed machines can be extremely challenging since it involves high frequency phenomena and mechanical considerations that are not commonly considered in conventional machine (e.g. rotor eddy current and rotor critical speeds). The focus of this paper is not on the mechanical aspects but it is important to mention that they can influence significantly the design and the electromagnetic performance of the machine [2]. Thus, rotor diameter and length as well as the necessity to use a retaining sleeve can limit the design options. Concerning the electromagnetic design, the need for fast and precise simulation tools has become more and more relevant over the years. Analytical models are an efficient way to tackle this problem. The computation time can be greatly reduced compared to finite element methods and they enable a deep understanding of the physics. In that category, subdomain models are particularly accurate $[3,4]$ since they can take into account the slotting effect and the eddy current reaction field [5]. In this paper, a 2-D analytical subdomain model such as the one described in [6] is used to evaluate the electromagnetic field in the machine.

\section{B. Machine Static Parameters Evaluation}

This subsection presents the evaluation of the static parameters of the machine: The back-EMF constant $K_{e}$, the resistance $R$ and the cyclic inductance $L_{s}$.

The resistance of a coil is evaluated using the machine geometrical parameters and the following equation:

$$
R_{\text {coil }}=\frac{\rho l_{a v}}{k_{f} S_{\text {slot }}}
$$

where $\rho$ is the copper electrical resistivity, $l_{a v}$ the average path of a coil turn, $\mathrm{S}_{\text {slot }}$ the slot area and $\mathrm{k}_{\mathrm{f}}$ the filling factor.

In order to compute $L_{s}$ and $K_{e}$, the flux over each slot for any rotor position is calculated using equation (10). The method is presented in [7] and applied here to a 2-layer winding.

$$
\phi_{i}=\frac{2 L_{s t}}{S_{\text {slot }}} \iint_{S_{i}} A_{i}(r, \theta) r d r d \theta
$$

where $S_{\mathrm{i}}$ is the domain of integration (left or right side of the slot), $L_{s t}$ the stack length and $A_{i}$ the magnetic vector potential given by the analytical model in the $i$-th slot. The calculated fluxes are then multiplied by a connecting matrix such the one described in [7] representing the winding connections and number of turns to obtain the phase fluxes $\psi_{A}, \psi_{B}$ and $\psi_{C}$. The inductance is calculated according to (11) by setting an arbitrary current in one phase of the machine and the remanent flux density of the magnet to zero.

$$
\begin{aligned}
L & =\frac{\psi_{A}}{I_{A}} \\
M & =\frac{\psi_{B}}{I_{A}}=\frac{\psi_{C}}{I_{A}} \\
L_{S} & =L-M
\end{aligned}
$$

where $L$ and $M$ are respectively the self and mutual inductance.

Using (10) and setting the armature currents to zero, the back-EMF constant $K_{e}$ is derived from (12) by taking the peak value of the fundamental component of the phase back-EMFs $E_{i}$ and dividing it by the rotating speed $\omega$.

$$
E_{i}=\omega \frac{d \psi_{i}}{d \theta_{r s}}
$$

where $\theta_{\text {rs }}$ is the rotor position.

$K_{e}, R$ and $L_{s}$ can now be used as input parameters to evaluate the inverter voltage and current waveforms.

\section{Machine Loss Evaluation}

This subsection aims to describe the different losses that occur in a high-speed surface-mounted permanent-magnet machine and how to mitigate them.

\section{1) Winding Copper}

Copper loss can be calculated as the product of the resistance by the squared rms current. However, this equation is valid when the fundamental frequency is low. At highfrequencies the skin effect in the conductor can lead to additional loss. They can be reduced by selecting a wire diameter lower than two skin depth.

Proximity effect caused by the nearby conductors on each other and eddy current induced by the rotating rotor PM can also lead to additional loss. Both effects can be mitigated by using Litz wire.

In this study, the copper losses are calculated using equation (13), assuming that the wire diameter can be freely selected and that the use of Litz wire is permitted.

$$
P_{C u}=3 R I_{r m s}^{2}
$$

where $I_{r m s}$ is the rms value of the phase current and $R$ the phase resistance which is calculated using (9) and the winding configuration. 


\section{2) Stator Iron}

Stator iron losses come from the variation of the flux density in the stator core. They are usually divided into three components: Hysteresis, eddy current and excess. Various equations with different degrees of complexity can be used to evaluate these losses [8].

In high-speed machines, stator iron losses can be reduced by selecting higher grade steel sheets and thinner lamination thickness. These machines also tend to have lower flux density in the stator iron.

In this paper, the Bertotti equation as described in [8] is used to compute the iron losses in the laminated stator core.

$$
P_{F e}=k_{h y} f^{2} B+k_{e c} f^{2} B^{2}+k_{e x} f^{3 / 2} B^{3 / 2}
$$

where $k_{h y}, k_{e c}$ and $k_{e x}$ are respectively the hysteresis, eddy current and excess loss coefficients given by the manufacturer, $f$ the fundamental frequency and $B$ the peak value of the flux density assuming a sinusoidal waveform.

\section{3) Mechanical}

In electric machines, mechanical losses are usually divided into two parts:

- Bearings: These losses are due to the friction in the bearing system. They are not described here since they rather depend on the design choice related to the application. As an example, high-speed ball bearings, air bearings or magnetic bearings can be used for this purpose.

- Windage: These losses are more specific to high-speed machines and are caused by the drag effects in the air gap of the machine. They can be significant when dealing with very high rotation speeds, large rotor diameters and small air gaps. These are described in detail in [9].

\section{4) Rotor Eddy Current}

The main subject of this paper is to propose a global optimization of both inverter and electric machine. From the machine side, the influence of the inverter topology and control strategy will impact copper losses, stator iron losses and rotor eddy current loss. The study is simplified in this paper by looking at the influence of the inverter and machine design on rotor losses only. This could seem to be an important simplification, but the PM losses are the main component of the rotor losses and it has a strong influence on the thermal behavior of the PM (possible demagnetization).

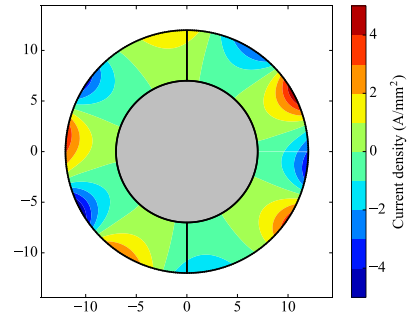

(a)

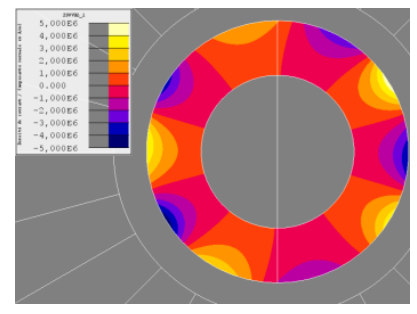

(b)
Fig. 3. Rotor eddy currents induced by sinusoidal currents in the magnet ring at $60 \mathrm{krpm}$ (a) Analytical model. (b) Finite element analysis.
Rotor losses occur because of spatial and time harmonics of armature currents as well as permeance variation due to the slotting effect. The induced currents in a moving conductive media such as a retaining sleeve, magnet ring or rotor yoke are responsible for additional losses. These losses are difficult to compute analytically since they involve the resolution of the diffusion equation taking into account the slotting effect. Simpler solutions can be found by using the following simplifications:

- Neglecting the slotting effect [4]: The armature currents alone are responsible for the losses.

- Neglecting the diffusion effect [10]: The loss will be overestimated since the skin effect is not considered. This method is commonly known as "resistance limited".

In this paper, a subdomain analytical model is used to evaluate the rotor eddy current loss. This model is resistance limited and account for the slotting effect. The rotor is made of a ferromagnetic yoke, a ring magnet and a non-conductive sleeve. A comparison of the calculated PM loss between the model and finite element analysis (FEA) is carried out to ensure that the skin effect is negligible in the studied case. For the ideal case of sinusoidal currents, the calculated magnet eddy currents for a $60 \mathrm{krpm}$ machine is given in Fig. 3 and is in good agreement with the FEA results.

\section{EleCtronic AND MaGnetic COUPLED Simulation}

\section{A. Electronic and Magnetic Coupled Procedure}

As show in Fig. 4, the electronic and magnetic models are combined to obtain a global response to required specifications. The design variables can then be selected to obtain an optimum trade-off between electronic and rotor losses. The complete coupled model scheme is detailed in the following sub-sections.

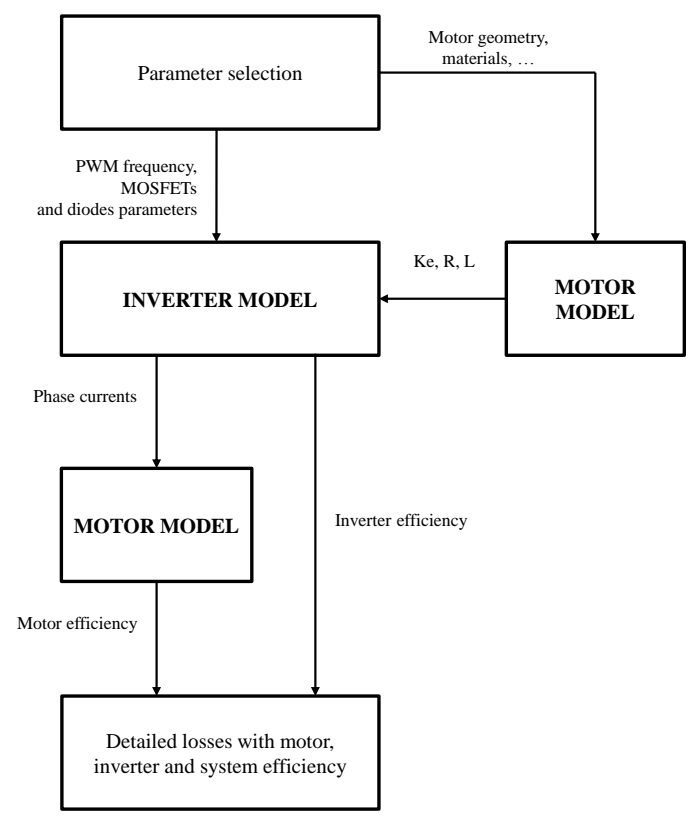

Fig. 4. Design flow chart of the high-speed drive design systems. 


\section{1) Design Parameters}

Study parameters are defined by the targeted application. The targeted overall dimensions usually give the maximum sizes of the electronic driver and the motor's stator radius. The system design parameters include the air gap for the motor, the switching frequency and modulation method for the electronic driver.

\section{2) Motor Parameters}

Motor static parameters such as phase inductance, phase resistance and phase flux linkage are computed by injecting perfect sinusoidal currents in motor phases. Inductance saturation cannot be obtained by the analytical motor model. Those parameters are transferred to the electronic calculation algorithm that computes the current which flows into motor phases.

\section{3) Electronic Calculation}

From the motor parameters and the DC bus voltage given in the specifications, the current is computed for a chosen PWM frequency and for space vector and discontinuous PWM modulation strategies [11]. The detailed MOSFET and diode losses are computed. The current harmonic spectrum is transferred to the motor calculation program.

\section{4) Motor Harmonic Calculation}

This motor algorithm takes the current spectrum provided by the electronic program. Harmonic calculation will be made to determinate the detailed rotor losses given by current harmonics.

\section{B. Case Study}

\section{1) Study Presentation}

A set of 3 PMSM machines with 6 slots, a 2-pole $\mathrm{NdFeB}$ ring magnet and concentrated windings have been selected to demonstrate the model capabilities. This design enables an easier control of the machine (low pole number) as well as a simplified manufacturing process (low slot number and toothcoil winding). The external stator radius, the power and the speed is defined by the application. The studied system is a $9 \mathrm{~kW}$ motor running at up to 60 '000 rpm, supplied by an inverter connected to a $400 \mathrm{~V}$ DC-bus using FOC a PWM frequency from $10 \mathrm{kHz}$ to $70 \mathrm{kHz}$. For the 3 machines, Table I, II and III show respectively the dimensions, the magnet properties and the static parameters calculated using the analytical model.

TABLE I. DIMENSIONS

\begin{tabular}{|l|c|c|c|l|}
\hline Parameter & Motor 1 & Motor 2 & Motor 3 & Unit \\
\hline Air gap & 3 & 1.5 & 0.5 & $\mathrm{~mm}$ \\
\hline Stack length & 70 & 57 & 40 & $\mathrm{~mm}$ \\
\hline Outer stator radius & \multicolumn{3}{|c|}{40} & $\mathrm{~mm}$ \\
\hline Rotor radius & \multicolumn{3}{|c|}{8} & $\mathrm{~mm}$ \\
\hline Stator yoke thickness & \multicolumn{3}{|c|}{30} & $\mathrm{~mm}$ \\
\hline Slot opening & \multicolumn{3}{|c|}{$\mathrm{deg}$} \\
\hline Magnet thickness & 5 & $\mathrm{~mm}$ \\
\hline
\end{tabular}

TABLE II. MAGNET PROPERTIES

\begin{tabular}{|l|c|l|}
\hline Parameter & Motor 1 -3 & Unit \\
\hline Remanent flux density & 1.18 & $\mathrm{~T}$ \\
\hline Relative permeability & 1.05 & - \\
\hline Electrical resistivity & 1.5 & $\mu \Omega . \mathrm{m}$ \\
\hline
\end{tabular}

TABLE III. STATIC PARAMETERS

\begin{tabular}{|l|c|c|c|l|}
\hline Parameter & Motor 1 & Motor 2 & Motor 3 & Unit \\
\hline Back-EMF constant & 31.66 & 31.04 & 30.46 & $\mathrm{mV} /\left(\mathrm{rad} . \mathrm{s}^{-1}\right)$ \\
\hline Resistance & 102.5 & 97.9 & 94.5 & $\mathrm{~m} \Omega$ \\
\hline Inductance & 284 & 288 & 301 & $\mu \mathrm{H}$ \\
\hline
\end{tabular}

\section{2) Electronic}

Electronic efficiencies are computed for the 3 motors. Since the different motor phase resistances and inductances are comparable, the effect on the calculated electronic efficiencies is insignificant. In Fig. 5, the influence of the PWM strategy is studied on the inverter efficiency. GDPWM presents an interesting benefit on efficiency for all PWM frequencies.

\section{3) Motor}

As shown in Fig. 6, the efficiency of all motors increases with higher PWM frequencies. Current harmonics generated in the motor are directly linked with the PWM frequency of the electronic driver. The natural low pass filter created by the phase resistance and inductance reduce high frequency current harmonic magnitudes and thus the losses. Rotor losses are computed and presented in Fig. 7. Motor 1 offers the highest efficiency and it reaches $93.4 \%$ from $30 \mathrm{kHz}$ for SVPWM. Fig. 7 also shows the influence of the air gap on the rotor losses. Motor 1 which has the widest air gap and offers remarkably low rotor losses ( $52 \mathrm{~W}$ when driven by a $30 \mathrm{kHz} \mathrm{PWM}$ ) is chosen to study the effect of the PWM strategy on the overall efficiency.

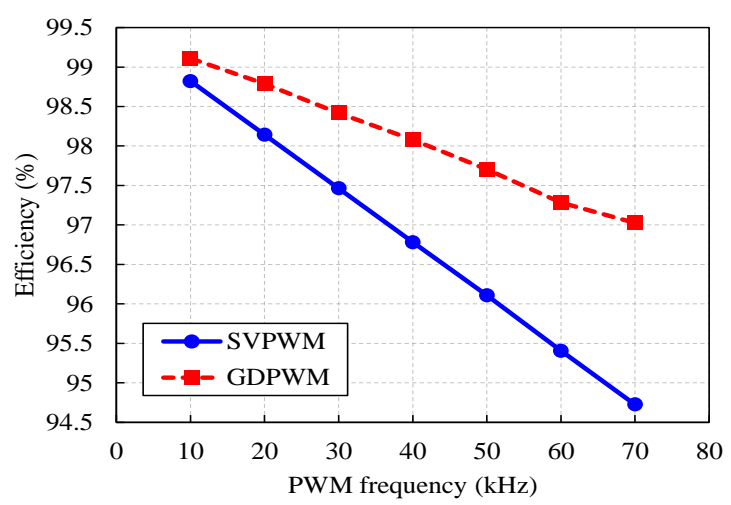

Fig. 5. SVPWM and GDPWM comparison on inverter effiency.

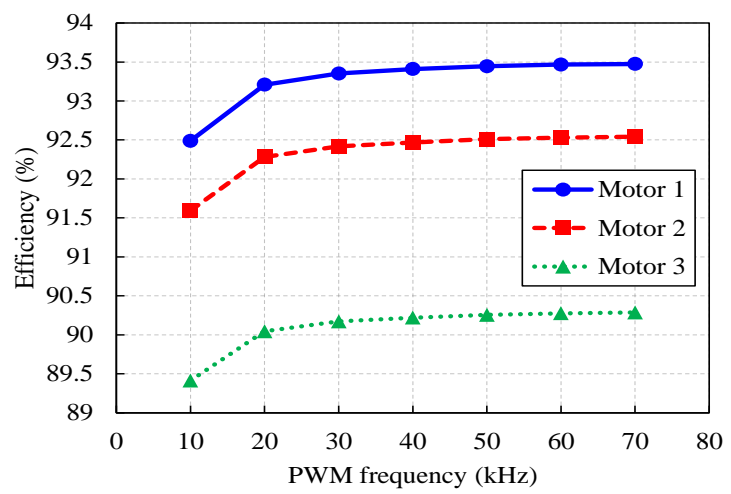

Fig. 6. Motor efficiencies versus PWM frequencies (SVPWM) 


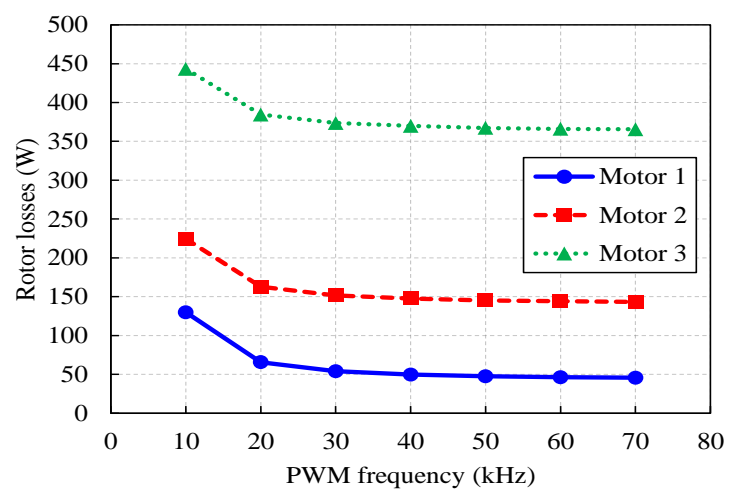

Fig. 7. Rotor losses versus PWM frequency (SVPWM) and motor topology.

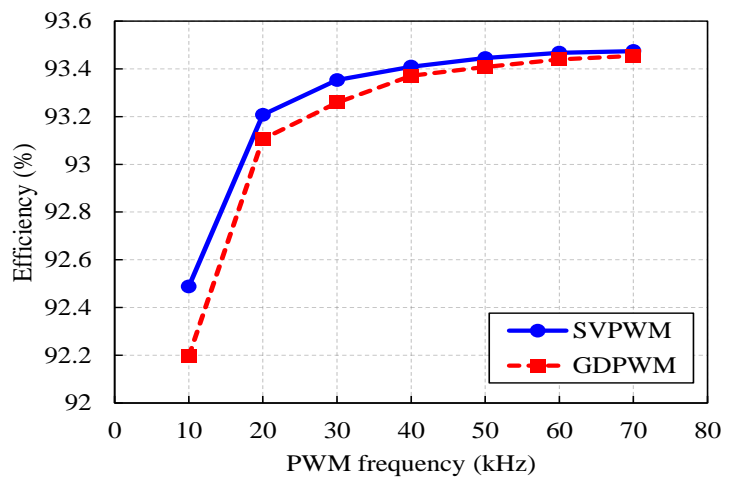

Fig. 8. SVPWM and GDPWM comparison on motor efficiency.

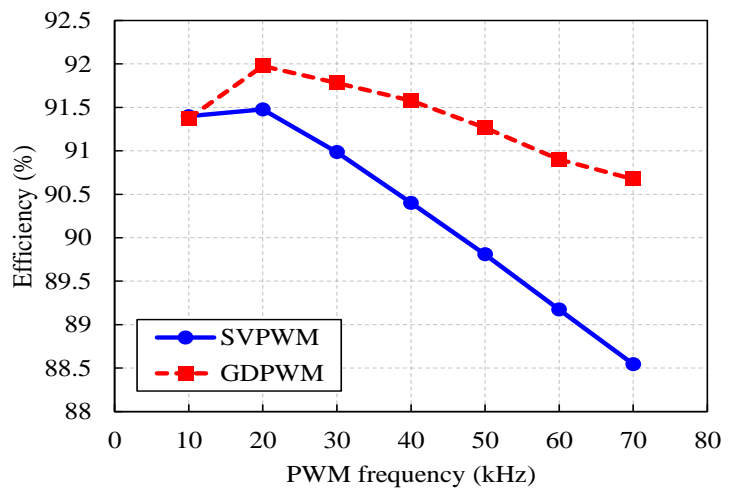

Fig. 9. SVPWM and GDPWM comparison on overall effiency.

\section{4) PWM Strategy Effects}

Then, we study the influence of the PWM strategy on the motor and overall efficiencies. As presented in Fig. 8, the motor efficiency with GDPWM is $0.11 \%$ lower for a PWM frequency of $30 \mathrm{kHz}$. Nevertheless, GDPWM substantially increases the electronic efficiency and thus the overall efficiency. Figure 9 shows that for the problem studied there, the maximum efficiency is obtained for a large air gap motor (to reduce rotor losses) and a $30 \mathrm{kHz}$ GDPWM. The motor efficiency is $93.3 \%$ and the electronic efficiency is $98.4 \%$ pushing the system to an overall efficiency of $91.8 \%$.

\section{CONCLUSION}

In this paper, a coupled electronic and electromagnetic model was described and applied to design a high-speed, high- power system with the goal of minimizing the rotor losses without degrading system performances. This alternative method offers fast responses to multiphysics problems which classically require time-consuming simulations. Thanks to this model, the influence of motor (air gap) and electronic parameters (PWM frequency and strategy) can easily be taken into account and varied to analyze the system behavior.

Future steps:

- An optimization algorithm could be implemented to provide a global optimization for multiple application specific requirements.

- The limitations of the rotor loss model must be evaluated for higher speeds and magnet properties.

- $\quad$ High-speed PM machines often require a retaining sleeve made of a conductive material (titanium alloy, stainless steel). The impact of this element on the rotor losses can be significant and could be include in this model to improve its reliability.

\section{REFERENCES}

[1] D. Lusignani, D. Barater, G. Franceschini, G. Buticchi, M. Galea, and C. Gerada, "A high-speed electrLic drive for the more electric engine," in 2015 IEEE Energy Conversion Congress and Exposition (ECCE), 2015.

[2] B. Riemer, M. Leßmann, and K. Hameyer, "Rotor design of a highspeed Permanent Magnet Synchronous Machine rating 100,000 rpm at 10kW," in 2010 IEEE Energy Conversion Congress and Exposition, 2010

[3] F. Dubas and C. Espanet, "Analytical Solution of the Magnetic Field in Permanent-Magnet Motors Taking Into Account Slotting Effect: NoLoad Vector Potential and Flux Density Calculation," IEEE Transactions on Magnetics, vol. 45, no. 5, May 2009.

[4] F. Dubas and A. Rahideh, "Two-Dimensional Analytical PermanentMagnet Eddy-Current Loss Calculations in Slotless PMSM Equipped With Surface-Inset Magnets," IEEE Transactions on Magnetics, vol. 50, no. 3, Mar. 2014.

[5] P. D. Pfister, X. Yin, and Y. Fang, "Slotted Permanent-Magnet Machines: General Analytical Model of Magnetic Fields, Torque, Eddy Currents, and Permanent-Magnet Power Losses Including the Diffusion Effect," IEEE Transactions on Magnetics, vol. 52, no. 5, pp. 1-13, May 2016.

[6] A. Gilson, S. Tavernier, F. Dubas, D. Depernet, and C. Espanet, "2-D Analytical Subdomain Model For High-Speed Permanent-Magnet Machines," presented at the International Conference on Electrical Machines and Systems (ICEMS), Pattaya, Thailand, 2015.

[7] T. Lubin, S. Mezani, and A. Rezzoug, "2-D Exact Analytical Model for Surface-Mounted Permanent-Magnet Motors With Semi-Closed Slots," IEEE Transactions on Magnetics, vol. 47, no. 2, Feb. 2011.

[8] D. Eggers, S. Steentjes, and K. Hameyer, "Advanced Iron-Loss Estimation for Nonlinear Material Behavior," IEEE Transactions on Magnetics, vol. 48, no. 11, Nov. 2012.

[9] A. Borisavljevic, "Limits, Modeling and Design of High-Speed Permanent Magnet Machines," University of Belgrade, 2011.

[10] L. J. Wu, Z. Q. Zhu, D. Staton, M. Popescu, and D. Hawkins, "Analytical Model for Predicting Magnet Loss of Surface-Mounted Permanent Magnet Machines Accounting for Slotting Effect and Load," IEEE Transactions on Magnetics, vol. 48, no. 1, Jan. 2012.

[11] A. M. Hava, R. J. Kerkman, and T. A. Lipo, "Carrier-based PWM-VSI overmodulation strategies: analysis, comparison, and design," IEEE Transactions on Power Electronics, vol. 13, no. 4, Jul. 1 